\title{
Structural changes in clays subjected to heat treatment: an analysis by structural refinement using the Rietveld method
}

\author{
M. Quiroga Agurto, E. L. Zeballos Velásquez, and F. A. Reyes Navarro \\ Facultad de Ciencias Físicas, Universidad Nacional Mayor de San Marcos, \\ Calle Carlos Germán Amezaga 375, Cercado de Lima, Perú. \\ *e-mail: mquirogaa@unmsm.edu.pe
}

Received 28 January 2021; accepted 26 April 2021

\begin{abstract}
Structural factors in clays influence their physical properties. Therefore, it is particularly important to understand the effects of heat treatment on the structure of the material during the ceramic process. This work analyzed clays from quarries located in the Cerro de Pasco region, Peru, evaluating their characteristics and the structural changes produced by heating, particularly in the interlaminar region.

The samples were thermally treated between $150^{\circ} \mathrm{C}$ and $800^{\circ} \mathrm{C}$ at intervals of $50^{\circ} \mathrm{C}$. In order to evaluate the structural changes produced by temperature, X-ray diffraction was carried out before and after each heat treatment. The qualitative analysis of the measurements allowed identifying the mineralogical composition of the samples, finding phases of calcium montmorillonite, kaolinite, illite, and quartz. The quantitative analysis by the Rietveld method found structural changes, particularly in the Ca-montmorillonite expansive clay. It was also possible to determine the decrease in the weight percentage of kaolinite till the collapse of its structure between $450^{\circ} \mathrm{C}$ and $500^{\circ} \mathrm{C}$. Illite presented greater thermal stability with slight variations in its weight percentage during heat treatment but without compromising its structure. Although the quartz phase did not show relevant structure changes, it slightly increased its weight percentage with increasing temperature.
\end{abstract}

Keywords: Clays; dehydration; X-ray diffraction; Rietveld method.

PACS: 61.05.-a; 61.10.Nz; 65.40.-b; 61.66.Fn

DOI: https://doi.org/10.31349/RevMexFis.67.061602

\section{Introduction}

Clays form a group of minerals with different characteristics and multiple technological applications. It is used for the elaboration of traditional ceramics and new materials useful today, too $[1,2]$. Its high plasticity is because water forms an envelope over the lamellar particles, producing a lubricating effect that facilitates the sliding of some particles over others when a strain is exerted on it. Clay minerals, when subjected to heating processes, undergo a series of transformations from dehydration to the appearance of a glassy phase.

The present work aims to analyze the structural changes, qualitatively and quantitatively, produced in clays because of temperature [3-5]. The structural evolution of the phases in each sample, a consequence of the heat treatment, was accompanied by measurements of X-ray diffraction (XRD) after each treatment [6,7]. The qualitative and quantitative analysis of the XRD measurements was performed by applying analytical methods and by structural refinement using the Rietveld method and the TOPAS program, which is particularly useful for the analysis of complex structures as in this case [8-10].

\section{Theoretical framework}

\subsection{The Hanawalt method}

It is used to identify the crystalline phases present in samples. This method takes the three most intense lines into account, permuting them with each other to minimize the problem of preferred orientation that can occur in sample analysis [11]. In the Hanawalt catalog, the values of the diffraction maxima of the substances are neatly registered. These maxima are compared with the interplanar distances $(d)$ and the relative intensities $\left(I / I_{0}\right)$ present in the diagrams obtained. The intensities $(I)$ are recorded in terms of their relative values, for which the value 100 is assigned to the most intense peak. The procedure for identifying a substance is detailed by the ICDD (International Center for Diffraction Data) [12]. Thus, three entries are considered for each substance, ordered according to the three lines of greater intensity. At present, there are several commercial and free computer programs based on the Hanawalt method. These programs use the PDF (Powder Diffraction File) database for the identification of materials.

\subsection{The Rietveld method}

Developed in 1967 by H. Rietveld, it is a refinement (adjustment) method of the crystal structure, focused on the characterization of single-phase and polyphase samples. It allows evaluating the microstructural aspects, such as crystallite size and microdeformation in various materials $[8,9]$. The fitting includes some criteria such as the lattice parameters of the material, space group, atomic sites, interplanar distances, as well as the effects of the equipment (known as instrumental effects), which are fitted during the refinement. This one is performed by comparing the calculated profile with the experimental diffraction profile. The former is generated by the initial structure model.

The refinement process was carried out by using the data 
obtained experimentally. These data are obtained from the sample measurement with the diffractometer, as well as from the data of the structure in order to obtain the calculated profile. Consequently, the simulation of the structure and its corresponding fitting to the experimental data can be performed. The refinement process is carried out by the least squares method between the observed (experimental) and calculated (model) patterns. The simulation stops after finding the best fit between the experimental data and the calculated one.

The analysis was done by using the TOPAS program, while the adjustment was performed by using the ThompsonCox-Hasting pseudo-Voigt function. [13]. The structure models for the identified phases were elaborated from the literature database [12]]. The refinement process has been applied for each phase and each measurement.

\section{Materials and methods}

The natural sample was collected in the Cerro de Pasco region, in a place usually explored by local artisans. This sample was prepared, pulverized, and separated into 15 subsamples to treat them thermally at different temperatures. The thermal treatment was carried out by using a three-stage oven, Model PT 1600.

The samples were treated at temperatures from $150^{\circ} \mathrm{C}$ to $800^{\circ} \mathrm{C}$ at intervals of $50^{\circ} \mathrm{C}$. The treatment time was 2 hours, with a rate of $50^{\circ} \mathrm{C} / \mathrm{min}$., in an air environment. Individual samples were used for each temperature and coded according to heat treatment, e.g., M-ST (sample without heat treatment); M-150 (sample at $150^{\circ} \mathrm{C}$ ), M-200 (sample at $200^{\circ} \mathrm{C}$ ), etc. In total, there were 15 samples investigated: the sample without heat treatment (used as a reference for analysis) and the other 14 samples treated thermally.

The XRD measurements were performed by using a Bruker diffractometer model D8 Focus in $\theta-2 \theta$ geometry. This diffractometer operated with $\mathrm{Cu}(\mathrm{K} \alpha)$ radiation, $0.1 \mathrm{~mm}$ receiver slit, $1-\mathrm{mm}$ divergence slit, $2.5^{\circ} \mathrm{C}$ soller slit, a detector of scintillation, a voltage of $40 \mathrm{kV}$, and current intensity of $40 \mathrm{~mA}$. The angle range was from $4{ }^{\circ} \mathrm{C}$ to $65^{\circ} \mathrm{C}$ with an angular step of $0.02^{\circ} \mathrm{C}$ and $4 \mathrm{~s}$ per step.

\section{Results and discussion}

The XRD measurements were performed before and after each heat treatment. Figure 1 and Table I show the results of the phase identification for the sample without heat treatment (M-ST), obtained by computational methods utilizing the PDF (Powder Diffraction File) database. This identification was confirmed by structural refinement applying the Rietveld method.

Figures $2 \mathrm{a}$ and $2 \mathrm{~b}$ show the enlarged sections of the original diffractograms corresponding to the samples treated up to $300^{\circ} \mathrm{C}$ and $500^{\circ} \mathrm{C}$, respectively. Thus, Figure $2 \mathrm{a}$ shows the changes in the intensity of the (001) peak of Camontmorillonite, at $2 \theta \approx 6.12^{\circ} \mathrm{C}$, as temperature increases. This intensity decreases until it disappears at $250^{\circ} \mathrm{C}$, while the intensity of the peak at $2 \theta \approx 8.9^{\circ} \mathrm{C}$ increases, which could be due to the contribution of the (001) peak of $\mathrm{Ca}$ montmorillonite in its new angular position. The change in position is due to the structural change of this phase, produced by its dehydration during the heat treatment, by losing water molecules lodged in the interlaminar region, causing a decrease in the interlaminar distance, which is expected in this clay due to its expansion and contraction properties [14]. These premises were considered in the analysis by structural refinement applying the Rietveld method.

TABLE I. Phases identified in the M-ST sample.

\begin{tabular}{ccc}
\hline Phase & Chemical Formula & PDF \\
\hline Quartz & $\mathrm{SiO}_{2}$ & $86-1628$ \\
Kaolinite & $\mathrm{Al}_{2}\left(\mathrm{Si}_{2} \mathrm{O}_{5}\right)(\mathrm{OH})_{4}$ & $83-971$ \\
Illite & $\mathrm{K}_{0.65} \mathrm{Al}_{2.0}\left[\mathrm{Al}_{0.65} \mathrm{Si}_{3.35} \mathrm{O}_{10}\right](\mathrm{OH})_{2}$ & $9-334$ \\
Ca-Montmorillonite & $\mathrm{Ca}\left(\mathrm{Ca}_{3}, \mathrm{Al}_{2}\right) \mathrm{Si}_{5} \mathrm{O}_{10}(\mathrm{OH})_{8}$ & $13-135$ \\
\hline
\end{tabular}

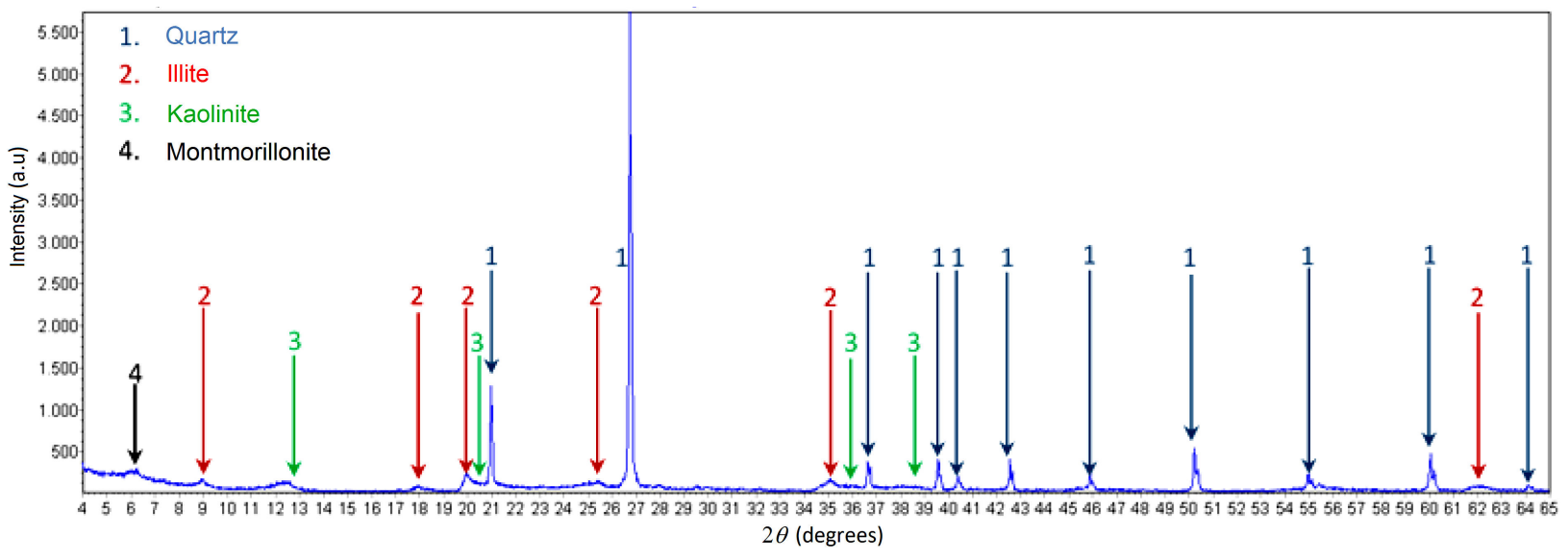

FIGURE 1. X-ray diffractogram showing the phases identified in the sample without heat treatment (M-ST). 

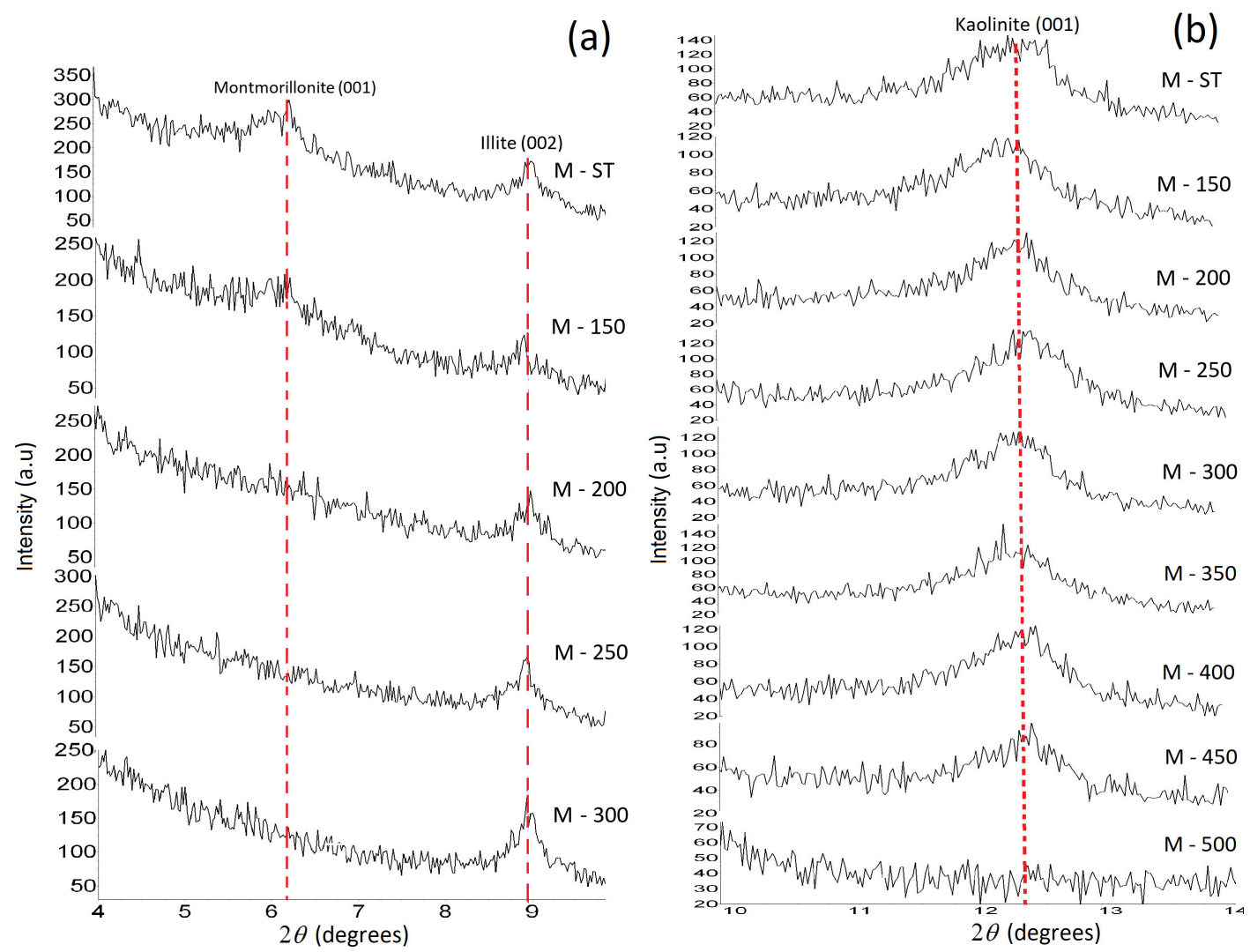

FIGURE 2. a) Decrease in intensity of the Ca-montmorillonite (001) peak as temperature increases. b) Decrease in intensity of the kaolinite (001) peak caused by the increase in temperature.

TABLE II. The weight percentage of the phases identified in each sample, obtained by the Rietveld refinement.

\begin{tabular}{ccccc}
\hline \multirow{2}{*}{ Sample } & \multicolumn{4}{c}{ Weight percentage (\%) } \\
\cline { 2 - 5 } & Montm. & Illite & Kaolinite & Quartz \\
\hline M-ST & 1.14 & 24.09 & 28.40 & 46.37 \\
M-150 & 1.11 & 24.61 & 29.65 & 44.63 \\
M-200 & 0.70 & 24.96 & 29.67 & 44.67 \\
M-250 & 0.61 & 23.16 & 30.08 & 46.15 \\
M-300 & 0.60 & 24.40 & 28.9 & 46.09 \\
M-350 & 0.54 & 25.45 & 25.70 & 48.31 \\
M-400 & 0.56 & 26.25 & 25.74 & 47.44 \\
M-450 & 0.65 & 31.31 & 17.45 & 50.59 \\
M-500 & 0.68 & 45.01 & & 54.31 \\
M-550 & 0.69 & 43.70 & & 55.61 \\
M-600 & 0.63 & 39.14 & & 60.23 \\
M-650 & 0.68 & 40.30 & & 59.01 \\
M-700 & 0.68 & 37.68 & & 61.64 \\
M-750 & 0.58 & 36.70 & & 62.71 \\
M-800 & 0.60 & 37.95 & & 61.44 \\
\hline
\end{tabular}

Figure $2 \mathrm{~b}$ shows the gradual decrease in the intensity of the kaolinite $(001)$ peak at $2 \theta \approx 12.43^{\circ} \mathrm{C}$, as the temperature increases, until it collapses between $400^{\circ} \mathrm{C}$ and $500^{\circ} \mathrm{C}[5,15]$. This phase loses water lodged in its structure as the temperature increases, transforming into metakaolinite through dehydroxylation.

Figure 3 shows the results of the Rietveld refinement for samples before and after heat treatment. The former corresponds to M-ST and the latter to M-150, M-250, M-450, and M-800. The respective diffractograms were selected because they show the important mineral changes that occurred due to heating.

Table II presents the weight percentages of the phases identified in each sample, obtained by structural refinement. There is a high percentage of quartz $(>44 \%)$ in all samples.

The Ca-montmorillonite structural refinement was carried out by considering its expansive nature. The change in the angular position of the Ca-montmorillonite (001) peak would be due to a decrease in the interlaminar distance $d$ associated with the (001) plane, a consequence of the heating, directly affecting the parameter $c$ of the unit cell. This parameter was refined for each sample treated at different temperatures, obtaining the values $d$ shown in Table 3 and Fig. 4. 


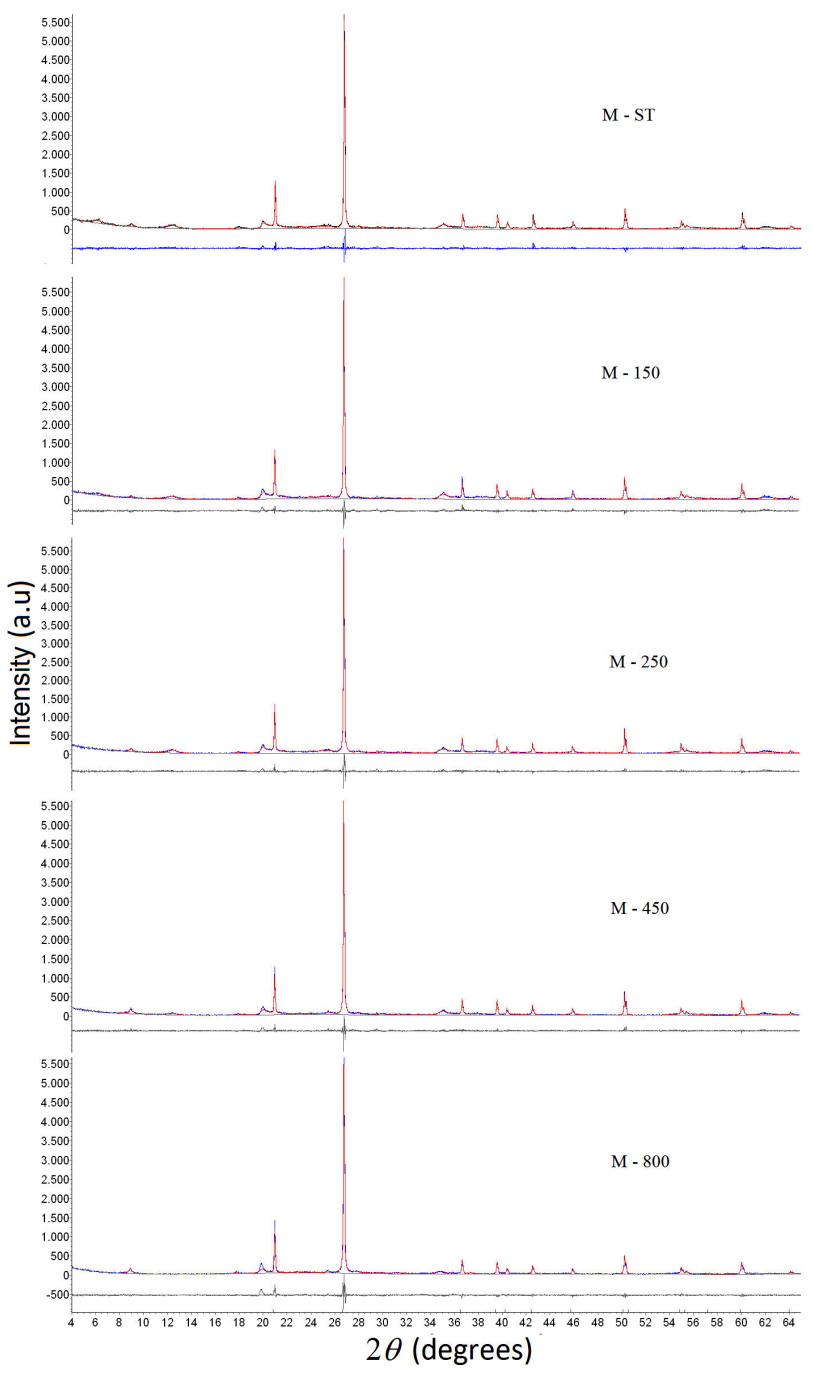

FIGURE 3. The Rietveld refinement corresponding to the samples before and after heat treatment at temperatures from $150^{\circ} \mathrm{C}$ to $800^{\circ} \mathrm{C}$.

As can be seen in Table III, the distance of $14.67 \AA$ before heat treatment is reduced to around $10.00 \AA$ after heating until $250^{\circ} \mathrm{C}$, showing a decrease of around $4.67 \AA$ due to loss of water molecules, particularly in the interlaminar region. According to the literature, calcium montmorillonites with interlaminar distances around $15 \AA$, as in this case, have a double layer of water molecules in the interlaminar region [16]. Since the average size of a water molecule is around $2.02 \AA$, the decrease in the interlaminar distance would be due to the removal of two layers of water, generating the dehydrated phase of Ca-montmorillonite and the modification of its structure. This last fact is evidenced in the $2 \theta$ position change of the $(001)$ peak, from $\approx 6.12^{\circ} \mathrm{C}$ to $\approx 8.9^{\circ} \mathrm{C}$. Figure 4 graphically shows this change.

In the literature, there are other results related to the structural behavior of Ca-montmorillonite with increasing temperature. Specifically, these results were obtained in previous studies for clay samples from the Nazca and Chulucanas
TABLE III. The values $d$ for Ca-montmorillonite in the samples treated up to $800{ }^{\circ} \mathrm{C}$, determined by refinement.

\begin{tabular}{cccc}
\hline Sample & $\boldsymbol{d}(\AA)$ & Sample & $\boldsymbol{d}(\AA)$ \\
\hline M-ST & $14.67 \pm 0.00$ & M-500 & $10.15 \pm 0.07$ \\
M-150 & $14.66 \pm 0.09$ & M-550 & $10.15 \pm 0.08$ \\
M-200 & $14.93 \pm 0.20$ & M-600 & $10.28 \pm 0.07$ \\
M-250 & $9.99 \pm 0.06$ & M-650 & $10.28 \pm 0.04$ \\
M-300 & $9.99 \pm 0.08$ & M-700 & $10.28 \pm 0.06$ \\
M-350 & $10.00 \pm 0.12$ & M-750 & $10.28 \pm 0.10$ \\
M-400 & $10.00 \pm 0.06$ & M-800 & $10.28 \pm 0.07$ \\
M-450 & $10.00 \pm 0.04$ & & \\
\hline
\end{tabular}

towns, in Peru [3-5]. Concerning the clays from Nazca [3], the value of $d_{001}$ for Ca-montmorillonite (15.37 $\AA$ before the thermal treatment) showed a slight decrease $(<0.6 \AA)$ with treatment up to $200^{\circ} \mathrm{C}$. In the interval from $200^{\circ} \mathrm{C}$ to $250^{\circ} \mathrm{C}$, this decrease was much greater $(>5.0 \AA)$ and the distance was reduced to $10.14 \AA$. As regards clays from Chulucanas [4,5], the value of $d_{001}$ for Ca-montmorillonite (14.86 $\AA$ before heat treatment) showed a decrease of around $5.0 \AA$ at $250^{\circ} \mathrm{C}$; the distance was reduced to $9.92 \AA$.

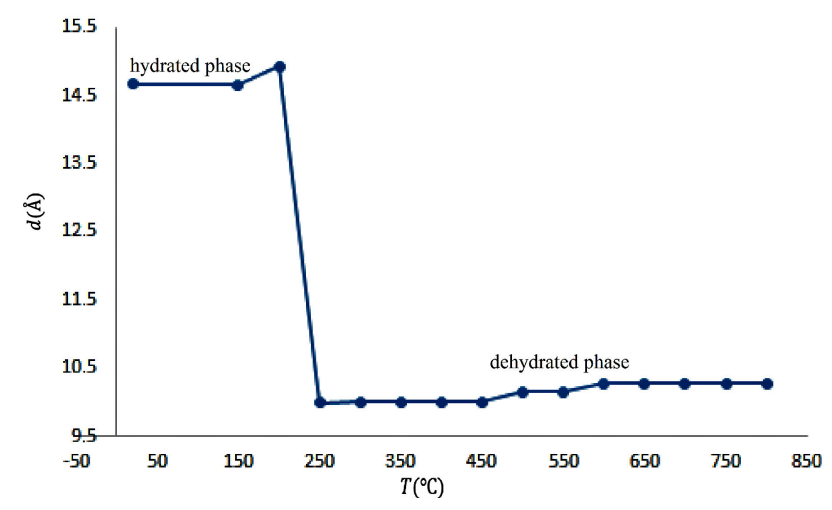

FIGURE 4. Ca-montmorillonite interlaminar distance as a function of temperature.

TABLE IV. The values $d$ for kaolinite in the samples treated up to $800{ }^{\circ} \mathrm{C}$, determined by refinement.

\begin{tabular}{cc}
\hline Samples & $\boldsymbol{d}(\AA)$ \\
\hline M-ST & 7.23 \\
M-150 & 7.19 \\
M-200 & 7.19 \\
M-250 & 7.18 \\
M-300 & 7.18 \\
M-350 & 7.18 \\
M-400 & 7.18 \\
M-450 & 7.18 \\
M-500 M-800
\end{tabular}


TABLE V. Indicators involved in the Rietveld refinement.

\begin{tabular}{cccccccc}
\hline Sample & $\mathrm{R}_{\mathrm{wp}}$ & $\mathrm{R}_{\exp }$ & $\mathbf{S}$ & Sample & $\mathrm{R}_{\mathrm{wp}}$ & $\mathrm{R}_{\exp }$ & $\mathbf{S}$ \\
\hline M-ST & 15.30 & 10.42 & 1.468 & $\mathrm{M}-500$ & 15.36 & 11.01 & 1.395 \\
M-150 & 15.52 & 10.60 & 1.464 & $\mathrm{M}-550$ & 15.51 & 10.99 & 1.411 \\
M-200 & 15.28 & 10.80 & 1.4145 & $\mathrm{M}-600$ & 16.83 & 10.71 & 1.571 \\
M-250 & 15.00 & 10.79 & 1.390 & M-650 & 15.19 & 10.95 & 1.387 \\
M-300 & 15.93 & 10.81 & 1.474 & M-700 & 15.48 & 11.01 & 1.406 \\
M-350 & 16.72 & 10.76 & 1.554 & M-750 & 16.03 & 10.92 & 1.468 \\
M-400 & 15.80 & 10.88 & 1.452 & M-800 & 15.97 & 11.18 & 1.428 \\
M-450 & 14.62 & 11.01 & 1.328 & & & & \\
\hline
\end{tabular}

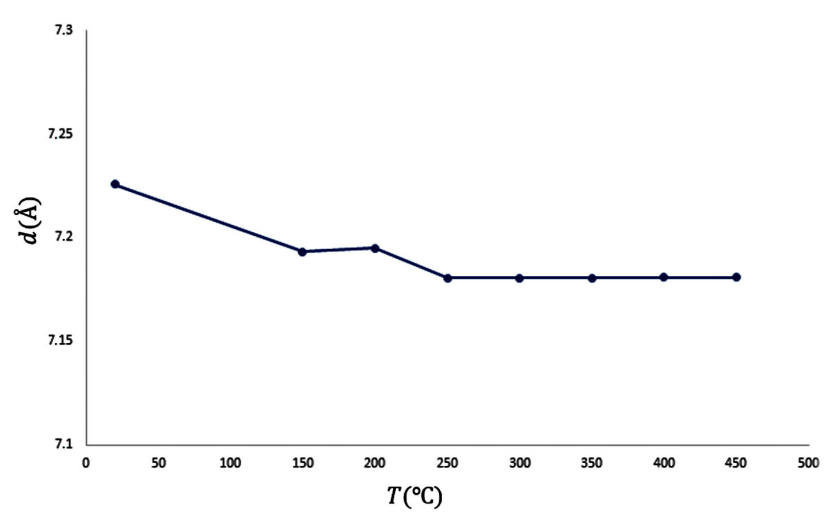

FIGURE 5. Kaolinite interlaminar distance as a function of temperature.

In the case of kaolinite, the behavior is different. Table IV and Fig. 5 show the results of the interlaminar distance, which does not show significant changes with increasing temperature. This behavior is expected because it is a non-expansive clay, in which the union between all its layers is solid enough to prevent the penetration of water molecules, thus avoiding swelling and, consequently, contraction with heating. Furthermore, Table II shows that the structure collapses after the treatment at $450^{\circ} \mathrm{C}$; other studies present similar results [4].

In the case of illite, Table II shows small variations in the weight percentage in the applied temperature range; the refinement did not report alterations in its structure. Regarding quartz, the results did not present structural changes due to heat treatment up to $800^{\circ} \mathrm{C}$; however, slight increases in its weight percentage are observed with heating (Table II). This could be interpreted as a greater crystallization of this phase with increasing temperature, producing an increase in the intensity of the diffraction peaks.

Concerning the indicators involved in each refinement, Table $\mathrm{V}$ shows the results for $\mathrm{R}_{\mathrm{wp}}$ (weighted profile residual), $R_{\exp }$ (expected profile residual), and $S$ (goodness-offit). This last indicator determines the quality of the refinement.

\section{Conclusions}

In the samples before heat treatment, the analyses revealed the presence of clayey phases such as Ca-montmorillonite $(1.14 \%)$, kaolinite $(28.40 \%)$, illite $(24.09 \%)$, and a large amount of quartz (46.37\%). After the respective heat treatment, structural changes were detected in the samples, particularly in the Ca-montmorillonite expansive clay that presented a change in its interlaminar distance $d$ associated with the (001) plane, from $14.67 \AA$ (room temperature) to 9.99 $\AA\left(250^{\circ} \mathrm{C}\right)$, due to the removal of the water molecules contained mainly in the interlaminar region, a characteristic of expansive clays. This observation explains, by observing the corresponding diffractogram, the change in the $2 \theta$ angular position of the peak associated with the (001) plane of $\mathrm{Ca}$ montmorillonite (from $\approx 6.12^{\circ} \mathrm{C}$ to $\approx 8.9^{\circ} \mathrm{C}$ ). In the cases of kaolinite and illite, these structural changes were not observed.

Furthermore, the gradual decrease of the kaolinite weight percentage could be observed, interpreting this result as the process towards the collapse of its structure between $450^{\circ} \mathrm{C}$ and $500^{\circ} \mathrm{C}$. Illite presented greater thermal stability with small variations in its weight percentage in the applied temperature range, but without compromising its structure. The quartz phase did not show structural changes with heating, but it had slight increases in its weight percentage with increasing temperature. Consequently, we can conclude that the quartz phase had a greater crystallization.

\section{Acknowledgments}

This work was carried out within the framework of a research project associated with the Crystallography Laboratory. The project was sponsored by the Universidad Nacional Mayor de San Marcos, with infrastructure support from the Faculty of Physical Sciences. 
1. J. Linares, F. Huertas, and J. Campel, La arcilla como material cerámico. Características y comportamiento (Clays as ceramic material. Characteristics and behavior), Revistas de la Universidad de Granada, Cuadernos de Prehistoria y Arqueología de la Universidad de Granada 8 (1983) 479-490. https://revistaseug.ugr.es/ index.php/cpag/article/view/1224

2. T.J. Pinnavaia, Expanded Clays and Other Microporous Solids. Eds. Mario L. Occelli and Harry E. Robson, first edition (Springer, US, 1992).

3. E.L. Zeballos, M.V. Miñano, P.C. Melero, E. Tello, A.L. Trujillo, and M.E. Mejía, Caracterización de arcillas de Nazca por difracción de rayos $X$ y refinamiento estructural por el método de Rietveld (Characterization of clays from the Nazca by $X$-ray difraction and structural refinament using the Rietveld method), Int. Electron. J. Nanoc. Moletrón. 11 (2013) 2001-2018. http://www.revista-nanociencia. ece.buap.mx/11nr1/Rev. 203Zeballos⒛pdf

4. P.C. Melero, Análisis del efecto térmico en la estructura de arcillas de Chulucanas por difracción de rayos-X, refinamiento Rietveld y técnicas complementarias (Analysis of the thermal effect on the clay structure of the Chulucanas town by X-ray diffraction, Rietveld refinement and complementary techniques), Licentiate thesis (UNMSM, Lima, Peru, 2015). https://cybertesis.unmsm.edu. pe/bitstream/handle/20.500.12672/4658/ Melero_sp.pdf? sequence=1\\&isAllowed=y

5. E.L. Zeballos, P.C. Melero, A.L. Trujillo, M.E. Mejía, and M. Ceroni, Estudio estructural de arcillas de Chulucanas por difracción de rayos X y método de Rietveld (A study on clay structure of samples from the Chulucanas town using $X$-ray diffraction and the Rietveld method). Revista Materia 19 (2014) 159-170. https://www.scielo.br/pdf/ rmat/v19n2/1517-7076-rmat-19-02-0159.pdf

6. H.P. Klug and L.E. Alexander, X-ray diffraction procedures for polycrystalline and amorphous materials (John Wiley \& Sons USA, 1974).
7. M.M. Moore and R.C. Reynolds Jr., X-ray diffraction and the identification and analysis of clay minerals, second edition (Oxford University Press, Oxford, 1997).

8. G. Will, Powder diffraction: the Rietveld method and the two stage method to determine and refine crystal structures from powder diffraction data. pp 41-48 (Springer-Verlag Berlin Heidelberg, Germany, 2006).

9. R.E. Dinnebier, A. Leineweber, and J.S.O. Evans, Rietveld Refinement: Practical Powder Diffraction Pattern Analysis using TOPAS (de Gruyter, 2019).

10. BRUKER AXS GmbH, Karlsruhe. Diffrac plus TOPAS v. 3.0 (Manual, 2006).

11. J.D. Hanawalt, H.W. Rinn, and L.K. Frevel, Chemical analysis by X-ray diffraction, Ind. Eng. Chem. Anal. Ed. 10 (1938) 457-513.

12. International center for diffraction data (ICDD), Inorganic crystal structure database (ICSD). https: / / www. icdd.com

13. T. Ida, M. Ando, and H. Toraya, Extended Pseudo-Voigt Function for Approximating the Voigt Profile, J. Appl. Cryst. 33 (2000) 1311-1316. https://doi.org/10. $1107 / \mathrm{S} 0021889800010219$

14. P. Bala, B.K. Samantaray, and S.K. Srivastava, Dehydration transformation in Ca-montmorillonite, Bull. Mater. Sci. 23 (2000) 61-67. https://doi.org/10.1007/ BF02708614

15. J. Garcia Guinea, V. Correcher, and F.J. Valle-Fuentes, Thermoluminescence of kaolinite, Radiat. Prot. Dosimetry 84 (1999) 507-510. https://doi.org/10.1093/ oxfordjournals.rpd.a032787

16. G. Odriozola and J.F. Aguilar, Stability of Ca-montmorillonite hydrates: A computer simulation study, J. Chem. Phys. 123 (2005) 174708. https://doi.org/10.1063/1. 2087447 